\title{
ESCOLAS MISTAS, ESCOLAS NORMAIS: A COEDUCAÇÃO E A FEMINIZAÇÃO DO MAGISTÉRIO NO SÉCULO XIX
}

\author{
June E. Hahner \\ State University of New York at Albany
}

\begin{abstract}
Resumo: A presente discussão objetiva explorar aspectos históricos sobre o lugar da coeducação no momento em que o magistério primário passou da ocupação majoritariamente masculina, em meados do século XIX, para a ocupação feminina, no século XX. A educação de meninas e a feminização do magistério, ocorridas ainda no século XIX, são analisadas no fluxo das reformas que aconteceram no final do século XIX e só podem ser entendidas a partir da ideia de modernização instaurada no país, na transição do século XIX para o século XX. Palavras-chave: coeducação; educação feminina; feminização do magistério.
\end{abstract}

No Brasil, como em muitos outros países do mundo ocidental, o magistério primário passou de ocupação majoritariamente masculina, em meados do século XIX, para a ocupação feminina, no século XX, sempre com diferenças nacionais. Sem negar a grande importância de fatores econômicos e do discurso do ensino como uma extensão da função maternal (o que também servia como desculpa para os baixos salários das maestras), quero explorar o papel da coeducação nessa transição no Brasil do século XIX, um papel talvez ambíguo mas importante.

Sim, foram homens as primeiras pessoas a serem nomeadas para as escolas públicas brasileiras nas primeiras décadas do século XIX. Mas isso não é surpreendente numa época em que a educação fora da casa era geralmente limitada aos meninos - e a muito poucos deles. Foi só em 1827 que vimos a primeira legislação a respeito da educação feminina, que determinou o estabelecimento de escolas para a população de todas as cidades e vilas do Império - tanto para meninas como para meninos -, mas que na realidade só existiu no papel, porque se registra apenas a criação de um pequeno número de escolas. ${ }^{1}$

Copyright () 2011 by Revista Estudos Feministas.

' Maria Thetes NUNES, 1962. 
Mas na década de 1870, uma década-chave, surgiu uma percepção da necessidade de reformas essenciais na organização da economia e do sistema político. ${ }^{2}$ Para os brasileiros que pregavam essa modernização material do Brasil, a educação seria um elemento essencial para o desenvolvimento do país, e eles apoiaram melhoramentos na educação feminina. No entanto, a ênfase ficou na maternidade, a qual eles ligaram ao progresso e ao patriotismo. Eles salientaram o poder da mulher para orientar o desenvolvimento moral de seus filhos e a formação de bons cidadãos para a Nação. Como argumentou o jurista cearense José Liberto Barroso, ${ }^{3}$ para que o Brasil conquiste sua grandeza e "cumpramse os seus altos destinos, é necessário educar a infância, e para educar a infância, é preciso educar a mulher, formar a mãe da família", tanto intelectual quanto moralmente. ${ }^{4}$ Assim, ligaram a educação da mulher à ideia do destino nacional.

Entre as ideias reformistas que surgiam no final da década de 1860, estava a "debatidíssima questão," nas palavras de Rui Barbosa, da coeducação. Mas foi só no fim da década de 1870 que a coeducação ganhou força, defendida com vários argumentos, incluindo o argumento econômico, um argumento empregado tanto nas escolas normais como nas escolas primárias. Enquanto as taxas nacionais de alfabetização masculina e feminina não estavam diminuindo nas últimas décadas do século, as taxas de alfabetização nas cidades em crescimento não só aumentavam, como a disparidade entre as taxas masculina e feminina diminuía progressivamente. No Rio de Janeiro, por exemplo, a taxa de alfabetização feminina comparada à masculina subiu de $29 \%$ feminina versus $41 \%$ masculina em 1872 a $44 \%$ feminina versus $58 \%$ masculina em $1890 .{ }^{5} \mathrm{O}$ crescimento do número absoluto de mulheres alfabetizadas nos centros urbanos mais desenvolvidos forneceu um grande potencial para a eleição de professoras que podiam ser contratadas por salários inferiores.

Os homens usufruíam de mais opções econômicas do que as que eram oferecidas às mulheres na mesma classe social. Essas melhores alternativas e oportunidades masculinas provavelmente contribuíam para a redução do número de potenciais professores homens no curso primário e até para alguns cancelamentos de classes, devido à ausência de professores masculinos. Por exemplo, depois de terem sido criadas três novas cadeiras para meninas e três para meninos no Rio de Janeiro, em 1876, quando foram abertas as inscrições para o concurso de professoras, o número de candidatas ultrapassou muito o número de candidatos homens, com a inscrição de 23 mulheres para as três cadeiras de meninas e só a inscrição de 12 homens para as três cadeiras de meninos. ${ }^{6} \mathrm{Com}$ poucas alternativas abertas às mulheres de certa instrução e status, ensinar era o desejado, embora os salários fossem inferiores aos dos homens. O ensino trouxe a algumas mulheres uma maior independência econômica, com relação àquela que poderiam ter alcançado de outro modo.

A coeducação também desempenhou um papel na feminização da instrução primária no Brasil. Criou mais oportunidades para mulheres entrarem no magistério porque se podia confiar a regência das aulas mistas às mulheres, e não limitá-las a só lecionar nas escolas para meninas. E a introdução da coeducação nas escolas normais aumentaria o

\footnotetext{
${ }^{2}$ Em Idéias em movimento: a geração de 1870 na crise do Brasil Império, de 2002, Angela Alonso empreende uma análise conjugada da experiência social da geração de 1870 e de seus textos, enfatizando sua dimensão política.

${ }^{3}$ José Liberto BARROSO, 1876, p. 100.

${ }^{4}$ Vide, também, A instrucção publica no Brazil (1867), de José Liberto Barroso, e Obra destinada a mostrar o estado em que se acha, e as reformas, que exige a instrucção publica no Brazil (1874), de Antonio de Almeida Oliveira.

${ }^{5}$ BRAZIL, 1906; e BRAZIL, 1922-1930.

${ }^{6}$ BRAZIL, 1876.
} 
número de mulheres e diminuiria o número de homens matriculados, mudando, assim, o futuro caráter da magistratura.

Em 1867, em sua crítica ao sistema educacional público brasileiro, Antonio de Almeida Oliveira ${ }^{7}$ propôs a coeducação, mas reconheceu a profunda oposição que isso representava. Enquanto a coeducação continuava sendo vista como suspeita, ou pelo menos desaconselhável às elites brasileiras, como em outros países católicos, ela era aceita apenas por uma questão econômica, particularmente em cidades onde o ensino separado entre os sexos demonstrava que os custos eram muito elevados. Com a expansão da educação nas duas décadas seguintes, o custo de manter o ensino primário separado para meninos e meninas e a escassez de professores homens estimularam a aceitação de classes mistas para crianças menores que não fossem das elites.

Seria ainda mais suspeita a coeducação nas escolas normais do que nas escolas primárias. Alguns educadores, como João Barbalho Uchôa Cavalcanti, inspetor geral da instrução pública de Pernambuco na década de 1870, onde se pretendeu criar num estabelecimento "para os dois sexos um curso normal comum e simultâneo", juntaram aos argumentos econômicos a favor das escolas mistas o da sua contribuição para "a amenidade dos costumes". Proclamaram que "reunir os alunos de ambos os sexos para ministrar-Ihes em comum o ensino é uma das providências mais vantajosas que se podem adoptar na instrução pública"; a rivalidade entre os dois sexos resultaria em "mais aplicação, mais assiduidade, melhores lições, mais proveito e adiantamento". Cavalcanti não só queria dar a preferência da regência das escolas primárias às senhoras, as quais tratariam como mães as crianças, mas achava que "as aulas mistas [...] a elas devem ser confiadas exclusivamente". ${ }^{8}$ Assim, foram criadas aulas mistas com mais crianças para as professoras ensinarem, maiores eram as possibilidades de aumentar o número de mulheres no magistério.

Devemos notar, porém, que as escolas primárias coeducativas não tomaram o lugar daquelas que segregavam por sexo - elas só se adicionavam às outras. Mesmo em algumas escolas designadas como mistas, meninos e meninas ficavam separados. As escolas protestantes eram mais propensas a instituir aulas mistas, como a Escola Americana em São Paulo, fundada em 1877 por missionários norte-americanos presbiterianos, que mais tarde virou o Mackenzie College, com "turmas mistas" desde o seu início. ${ }^{9}$ Mas a coeducação continuava não sendo bem aceita pelas famílias das elites para os seus próprios filhos.

No outro extremo da pirâmide educacional das escolas primárias, vale dizer, nas faculdades, encontramos um debate paralelo na década de 1870. Nesse nível, não se falava de escolas mistas, mas do ingresso da mulher nas faculdades de Medicina. Além das defensoras mulheres dos direitos femininos e da "emancipação da mulher," vimos defensores do direito da mulher de estudar Medicina como Tobias Monteiro. ${ }^{10}$ Ele não apenas contestava teorias fisiológicas baseadas no tamanho do cérebro feminino, mas também citava exemplos de mulheres europeias que concluíram os estudos de Medicina.

Alguns médicos propícios ao ingresso da mulher nas escolas de Medicina no Brasil, como Joaquim Monteiro Caminhoá, da Faculdade de Medicina do Rio de Janeiro, em 1874, não só destacavam o número de mulheres médicas na Europa e nos Estados Unidos - numa época em que era comum utilizar exemplos estrangeiros nos argumentos -, mas também sustentavam que mulheres de pudor excessivo escondiam certas enfermidades de seus médicos, porque temiam ser examinadas por homens. ${ }^{11}$

\footnotetext{
7 OLIVEIRA, 1874.

8 João Barbalho Uchôa CAVALCANTI, 1875b, p. 22-23.

- Fernando de AZEVEDO, 1958, p. 620.

${ }^{10}$ Tobias MONTEIRO, 1962.

11 BRAZIL, $1875 \mathrm{c}$.
} 
Em 1879, numa continuação do movimento de reformismo dos anos 1870 , o Ministério Liberal do Visconde de Sinimbu baixou a chamada Reforma Leôncio de Carvalho do ensino primário e secundário da Corte e do ensino superior em todo o Império, uma reforma que continuaria sendo válida até o fim do Império. Essa não só dispensou os não católicos de aulas de religião e abriu o sistema de ensino para a iniciativa privada, prometendo mudar o espírito da formação superior, mas liberava a matrícula de mulheres nas faculdades de Medicina e previa escolas mistas. Ampliou o currículo das escolas normais e estabeleceu a possibilidade de escolas normais nas províncias. ${ }^{12}$

A primeira escola normal para treinamento de professoras primárias, uma ideia europeia, tinha surgido em Niterói, em 1835, numa tentativa de melhorar o padrão de ensino. Nas décadas seguintes, foi seguida por outras em várias províncias e na Corte, embora as primeiras escolas normais fossem destinadas só para homens. Como abriam ou fechavam dependendo de decisões políticas, as escolas normais permaneceram em pequeno número, com poucas matrículas e com uma posição precária até os últimos anos do Império. No Rio de Janeiro e em São Paulo, por exemplo, onde seções para mulheres foram estabelecidas na década de 1870, as escolas normais fecharam e só reabririam em 1880, depois da Reforma Leôncio de Carvalho, como escolas mistas. ${ }^{13}$

Enquanto se podia pensar que a Reforma Leôncio de Carvalho de 1879, reforma que abriu as faculdades de Medicina às mulheres, pudesse ter facilitado a aceitação e a implementação da coeducação, a oposição às aulas mistas continuava. Esse mesmo decreto impôs limites: mandou receber os meninos nas escolas do sexo feminino só até chegarem à idade de 10 anos e, nas faculdades de Medicina, determinou que, para "os indivíduos do sexo feminino [...], haverá nas aulas lugares separados". ${ }^{14}$ Já sabemos como as escolas primárias públicas serviam só às camadas menos favorecidas da sociedade. $\mathrm{E}$ o grupo de mulheres pioneiras que frequentavam as faculdades de ensino superior não só era muito pequeno, mas frequentemente encontrava hostilidade masculina e palavras que cortavam "como punhais", segundo a redatora de um jornal dirigido a um público feminino. ${ }^{15}$ Fora mulheres corajosas como essa, as mulheres das elites frequentavam instituições de ensino secular ou religioso só de mulheres.

Como alguns brasileiros, Rui Barbosa, que aceitou o regime da coeducação na escola elementar e concordou com o ingresso da mulher nas faculdades, afirmou que

desde o primeiro alvorecer da adolescência até a completa constituição sexual da mulher, dos 11 aos 18 anos, é fisiologicamente um mal de incalculável alcance e irremediáveis resultados educá-la nos mesmos bancos, sob a mesma organização pedagógica, debaixo do mesmo regime disciplinar que o homem. ${ }^{16}$

Mas as exigências econômicas predominavam no caso das escolas normais. Nesse nível, das escolas normais que não recebiam os filhos das elites, as dificuldades financeiras em manter escolas separadas para homens e mulheres e ao mesmo tempo fortalecer o magistério também conduziam para a premência de escolas normais mistas. Um ano depois da introdução da Reforma Leôncio de Carvalho, que incentivou a criação de escolas mistas bem como o estabelecimento de mais escolas normais, as escolas normais da Corte, para as quais o Decreto de 1876 tinha estabelecido duas escolas separadas para os dois

\footnotetext{
12 BRASIL, 1879, Anexo A.

${ }^{13}$ Leonor Maria TANURI, 1979. Ver também BRAZIL, 1880a, p. 25-28; Maria Teresa CANEZIN e Walderês Nunes LOUREIRO, 1994; Primitivo MOACYR, 1939; e SÃO PAULO, 1881, p. 22.

14 BRAZIL, 1879, Anexo A, p. 1-15.

${ }^{15}$ Andradinha América de OLIVEIRA, 1912, p. 224.

${ }^{16}$ Rui BARBOSA, 1947, p. 30.
} 
sexos, e a escola normal de São Paulo foram recriadas como escolas mistas, e a escola normal da Província do Rio de Janeiro foi convertida em escola mista. Na primeira turma a matrícula de mulheres superou a dos homens. Do total de 22 escolas normais funcionando nas províncias em 1882, 15 eram escolas mistas, enquanto só cinco eram restritas aos homens e duas às mulheres. ${ }^{17}$

A introdução da coeducação na Escola Normal da Corte resultaria em mudanças que iriam promover a feminização do magistério primário, além de não causar os problemas temidos por defensores de escolas separadas para os dois sexos, como questão de moralidade. Pelo menos, como notou Motta de Azevedo no seu relatório enviado à Primeira Exposição Pedagógica do Rio de Janeiro de 1882, ele já tinha visitado "muitas escolas do sistema misto nos Estados Unidos", onde viu o "aspecto calmo, serio, concentrado e respeitoso" dos alunos "dentro da mesma aula [...] sentados promiscuamente". No Brasil "a coeducação dos sexos, admittidos nas escolas normaes da Corte, de São Paulo e outras provincias, não tem produzido nenhum dos inconvenientes do que receiam as antagonistas desse sistema". ${ }^{18}$

Na Escola Normal da Corte, a percentagem de alunas não só cresceu rapidamente, mas, segundo o seu diretor em 1883, "são elas que mais concorrem às aulas e melhores notas conquistam nos exames". ${ }^{19} \mathrm{E}$ talvez isso também tenha desestimulado a matrícula de mais homens. Como notou o diretor da instrução pública no Rio de Janeiro, Antonio Herculano de Souza Bandeira Filho, um defensor de escolas normais separadas para os dois sexos, uns anos depois da introdução da coeducação na Escola Normal da Corte, o resultado da introdução da coeducação foi "inesperado. Deu-se um desequilíbrio entre a frequencia dos alunos dos dois sexos; o sexo masculino desceu a um algarismo diminuto, ao passo que o primeiro subiu de modo que, quem visita a escola suppõe no primeiro momento que ela é exclusivamente destinada às mulheres". ${ }^{20}$

A Reforma Leôncio de Carvalho também deu prioridade para a contratação de professoras, falando da criação de jardins da infância para os dois sexos que seriam fundados na Corte e "confiados à direção de professoras". As aulas mistas, como muitos reconheceram, podiam ser ministradas por mulheres, as quais eras as "educadoras naturais". Assim, a maternidade espiritual serviu como uma justificativa para empregar mais, e mais barato, professoras. Se, por um lado, os novos regulamentos possibilitaram a oportunidade de terem professoras para aquele grupo de alunos que recebiam aulas apenas de professores homens, por outro lado, essas normas podiam incitar a competição entre os dois grupos de professores. Isso ajudou, sem dúvida, no processo de feminização da sala de aula.

A preferência por professoras foi reforçada, pelo menos na Escola Normal da Corte, com a presença de positivistas, especialmente o tenente Benjamin Constant Botelho de Magalhães, professor da Escola Politécnica e então da Escola Normal, que desempenhou um papel importante em 1881 ao refazer o currículo da Escola Normal, refletindo uma hierarquia positivista de estudos acadêmicos. Poucos anos depois, ele serviu, por um breve período, como diretor interino da Escola Normal do Rio, acumulando tal função à de professor de Matemática, que exerceu por mais anos. Os positivistas, ao mesmo tempo que pregavam a inferioridade orgânica e intelectual da mulher, aclamavam a superioridade moral

\footnotetext{
${ }^{17}$ BRAZIL, 1880a e 1880b; BRAZIL, 1881, p. 22; e BRAZIL, 1883, p. 7.

${ }^{18}$ BRAZIL, 1884b, p. 235. Na sua introdução a esse volume, Leôncio de Carvalho, primeiro secretário da comissão designada a organizar um congresso de professores junto com essa exposição, afirma que $\circ$ Parlamento Imperial nunca reservou a verba para o congresso acontecer.

${ }^{19}$ BRAZIL, 1883, p. 9.

${ }^{20}$ BRAZIL, 1884a, p. 3-4.
} 
feminina. Por isso Benjamin Constant informou ao corpo docente da Escola que o ensino primário era uma "professão que deve pertencer exclusivamente à mulher". Ele notou a "constante e notável preponderância em quantidade e em qualidade das alunas em relação aos alunos" na escola normal. ${ }^{21} \mathrm{E}$ bem antes de o século terminar, seria difícil achar professores primários homens. Embora o governo republicano tivesse afirmado a coeducação na escola normal na primeira década do século XX, de 1901 a 1907, a matrícula na escola normal do Rio foi vedada aos homens, ${ }^{22}$ assim contribuindo à feminização do magistério primário. No Rio de Janeiro, em 1872, as mulheres representavam um terço do professorado, e essa cifra dobrar-se-ia até o começo do século XX; em 1906, as mulheres compreenderiam $70 \%$ dos professores da capital. ${ }^{23}$

Até o fim da década seguinte, a feminização do magistério já era fato. Mas ainda que os homens tivessem saído das salas de aula, não saíram do poder sobre o ensino. Por mais de décadas eles seriam os inspetores das escolas primárias, manteriam a superioridade na administração do ensino superior e estabeleceriam as políticas da educação em todos os níveis. A feminização do ensino primário não foi simples.

\section{Referências bibliográficas}

ALONSO, Angela. Idéias em movimento: a geração de 1870 na crise do Brasil Império. São Paulo: Paz e Terra, 2002.

AZEVEDO, Fernando de. A cultura brasileira. São Paulo: Melhoramentos, 1958.

BARBOSA, Rui. Obras completas de Rui Barbosa. Rio de Janeiro: Ministério da Educação e Saúde, 1947. v. X. Tomo III. Reforma do ensino primário.

BARROSO, José Liberto. A instrucção publica no Brazil. Rio de Janeiro: Tipografia Nacional, 1867.

. Conferencias populares. Rio de Janeiro: J. Villeneuve, 1876.

BRAZIL. Diretoria Geral de Estatística. Recenseamento da população do Império do Brazil a que se procedeu no dia 1 de agosto de 1872. Rio de Janeiro: Leuzinger, 1873-1876.

. Ministerio do Imperio. Relatorio apresentado à Assemblea Geral Legislativa na quarta sessão da decima quinta legislatura pelo ministro e secretario d'Estado Dr. João Alfredo Corrêa de Oliveira. Rio de Janeiro: Typ. Nacional, 1875a.

. Relatorio que ao exm. Sr. Presidente da provincia apresentou o inspector geral da instrucção publica João Barbalho Uchôa Cavalcanti em 30 de janeiro de 1875. Recife: Typ. de Manoel Figueiroa de Farias \& Filho, 1875b.

. Ministerio do Imperio. Relatorio apresentado à Assemblea Geral Legislativa na quarta sessão da decima quinta legislatura pelo ministro e secretario d'Estado Dr. João Alfredo Corrêa de Oliveira. Rio de Janeiro: Typ. Nacional, 1875c.

. Lista de candidatos que concorreram às provas escritas. Barão de São Felipe, Inspector Geral de Instrução, para José Bento da Cunha e Figueiredo, Ministro de Negocios do Imperio. Rio de Janeiro, 30 de setembro de 1876. Arquivo Nacional IE5 59.

Actas e pareceres do Congresso de Instrucção do Rio de Janeiro. Relatorio apresentado ao. exm. sr. presidente da provincia em 31 de outubro de 1878 pelo inspector João Barbalho Uchôa Cavalcanti. Recife: Typ. de Manoel Figueroa de Paiva \& Filho, 1878.

\footnotetext{
${ }^{21}$ Benjamin Constant Botelho de Magalhães a João Pedro de Aquino (RIO DE JANEIRO, 1886).

${ }^{22}$ Alfredo Balthazar da SILVEIRA, 1954.

${ }^{23}$ BRAZIL, 1873-1876; e BRAZIL, 1907
} 
- Ministerio do Imperio. Relatorio apresentado à assemblea geral legis/ativa na segunda sessão da decima setima legis/atura pelo ministro e secretario de estado dos negocios do Imperio conselheiro Leôncio de Carvalho. Rio de Janeiro: Typ. Nacional, 1879.

- Ministerio do Imperio. Relatorio apresentado à assemblea geral pelo ministro e secretario do ministerio do imperio Conselherio Barão Homem de Mello. Rio de Janeiro: Typ. Nacional, 1880a.

Relatorio do presidente João Marcelino de Souza Gongaga apresentado à legislativa provincial de 8 de setembro de 1880. Rio de Janeiro: Typ. Montenegro, 1880b. 1881 .

Relatorio apresentado à assemblea legis/ativa provincial de S. Paulo. Rio de Janeiro,

. Ministerio do Imperio. Relatorio apresentado à Assemblea Geral Legis/ativa na terceira sessão da decima oitava legis/atura pelo ministro e secretario de estado nos negocio dos Imperio Pedro Leão Velloso, Anexo C. Relatorio dos successos mais notaveis do ano lectivo de 1882 na Escola Normal da Corte apresentado à congregação da mesma escola em sessão de 5 de maio de 1883 por Joaquim Borges Carmo. Rio de Janeiro: Typ. Nacional, 1883.

. Actas e pareceres do Congresso de Instrucção do Rio de Janeiro. Rio de Janeiro:

Typ. Nacional, 1884a. p. 3-4. Parecer do Dr. Antonio Herculano de Souza Bandeira Filho. . Primeira exposição pedagógica do Rio de Janeiro: documentos. Rio de Janeiro:

Typ. Nacional, 1884b. 1906.

Diretoria Geral de Estatística. Recenseamento do Rio de Janeiro... Rio de Janeiro,

Diretoria Geral de Estatística. Recenseamento do Rio de Janeiro (Distrito Federal) realizado em 20 de setembro de 1906. Rio de Janeiro: Officina da Estatística, 1907.

. Diretoria Geral de Estatística. Recenseamento do Brazil realizado em 1 de setembro de 1920. Rio de Janeiro: Typ. da Estatistíca, 1922-1930.

CANEZIN, Maria Teresa; LOUREIRO, Walderês Nunes. A escola normal em Goiás. Goiânia: Ed. UFG, 1994.

MOACYR, Primitivo. A instrução e as províncias: subsídios para a historia da educação no Brasil. São Paulo: Companhia Editora Nacional, 1939.

MONTEIRO, Tobias. Estudos sociológicos. Rio de Janeiro: Instituto Nacional do Livro, 1962.

NUNES, Maria Thetes. Ensino secundário e sociedade brasileira. Rio de Janeiro: Instituto de Estudos Brasileiros, 1962.

OLIVEIRA, Andradinha América Andrade de. Divorcio? Porto Alegre: Livraria Universal, 1912.

OLIVEIRA, Antonio de Almeida. Obra destinada a mostrar o estado em que se acha, e as reformas, que exige a instrucção publica no Brazil. Maranhão: Ed. do Pais, 1874.

RIO DE JANEIRO. Relatorio... apresentado à congregação da Escola Normal da Corte. Rio de Janeiro, maio de 1886. Arquivo do Instituto de Educação de Governo do Estado do Rio de Janeiro. Benjamin Constant Botelho de Magalhães a João Pedro de Aquino.

SÃO PAULO. Relatorio apresentado à assemblea legislativa provincial de S. Paulo pelo presidente da provincia Laurindo Abelardo de Brito no dia 13 de janeiro de 1881. Santos: Typ. A Vapor do Diario de Santos, 1881.

SILVEIRA, Alfredo Balthazar da. História do Instituto de Educação. Rio de Janeiro: Prefeitura do Distrito Federal, 1954.

TANURI, Leonor Maria. O ensino normal no Estado de São Paulo, 1890-1930. São Paulo: USP, 1979.

[Recebido em 25 de agosto de 2010 e aceito para publicação em 16 de dezembro de 2010] 
Mixed and Normal Schools: Coeducation and the Feminization of Teaching in Brazil in the 19th Century

Abstract: The discussion here presented aims at exploring historical aspects of the place of coeducation at the moment that elementary school teaching changed from a predominantly male occupation, in mid-nineteenth-century, to a feminine career in the 20th century. The education of girls and the feminization of teaching are analyzed as part of the reforms which took place at the end of the 19th century and which can be understood in the context of the spirit of modernization which characterized Brazil at the turn of the last century.

Key Words: Coeducation; Education of Women; Feminization of Teaching. 